\title{
Structure and Function of Natural-Killer-Cell Receptors
}

\begin{abstract}
The function of natural-killer (NK) cells is modulated by the balance between a number of activating and inhibitory receptors. Killer immunoglobulinlike receptors (KIRs) are mostly inhibitory receptors. They play a critical role in recognizing self-class-I major histocompatibility complex (MHC) molecules and thus protect healthy host cells from NK-targeted lysis. In contrast, both NKG2D and CD16 are activating NK receptors that trigger the NK-cell lysis of various tumor and virally infected cells through either direct ligand engagement or antibody-dependent cellular cytotoxicity (ADCC). Through structural studies of members of these distinct receptor families, in particular, the structure and recognition between KIR2DL2 and HLA-Cw3, that between NKG2D and ULBP3, and that between CD16 and IgG Fc, considerable understandings have been achieved about their function and their ligand recognition.
\end{abstract}

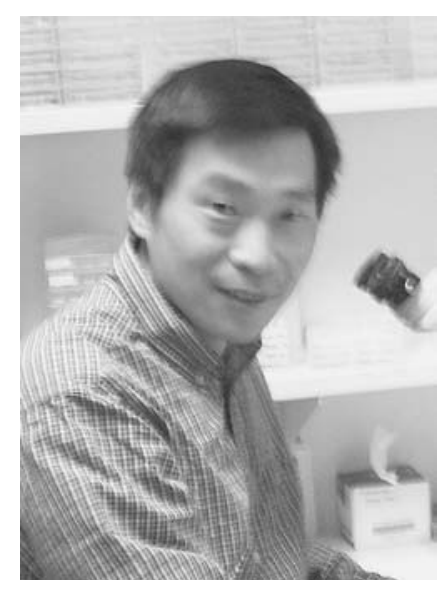

Peter D. Sun

Structural Immunology Section, Laboratory of Immunogenetics, National Institute of Allergy and Infectious Diseases, National Institutes of Health, Rockville, MD

\section{Key Words}

KIR

NKG2D

$\mathrm{Fc}$ receptors

Crystal structure

Immunoreceptors

NK receptors

\section{Molecular Recognition Between KIR and HLA Distinguishes Self from Non-Self}

Natural-killer (NK) cells constitute an important part of the innate immune system and are able to respond more rapidly than cells of adaptive immunity. It is known that the cytolytic activity of NK cells is tightly regu- lated by an array of activating and inhibitory receptors on the cell surface. The inhibitory receptors primarily recognize class I major histocompatibility complex (MHC) molecules $(1,2)$. Structurally, they comprise two distinct superfamilies: C-type lectinlike (CTLR) and immunoglobulinlike. Murine Ly49 receptors are thought to be the functional orthologs of 
human killer immunoglobulinlike receptors (KIRs).

Killer-cell immunoglobulinlike receptors are type I transmembrane glycoproteins with two or three extracellular C2-type immunoglobulin domains $(3,4)$. The inhibitory forms contain immunoreceptor-tyrosine-based inhibitory motifs (ITIM) in their cytoplasmic tail and the noninhibitory forms have a shorter cytoplasmic tail and contain a positively charged residue in the transmembrane region $(1,2)$. Human KIRs are encoded by approximately 12 genes located in the leukocyte receptor complex (LRC) region on chromosome 19q $(5,6)$. A similar number of KIR genes have been identified in other primate species (7). Among other KIRlike cell surface receptors, immunoglobulinlike transcript (ILT) or LIR contain two or four Ig-like domains (8-10), leukocyte-associated Ig-like receptors (LAIR-1 and LAIR-2) contain a single Ig-like domain (11), and paired Ig-like receptors (PIR-A and PIR-B) contain six Ig-like domains (12-14). They display $35-50 \%$ sequence identity with KIR and are part of the KIR superfamily.

The first crystal structure of a KIR/human leukocyte antigen (HLA) complex was that of KIR2DL2 bound to HLA-Cw3 with a nonamer self-peptide GAVDPLLAL (GAV) from importin- $\alpha 1$ (15) (Fig. 1). The structure revealed a common $1: 1$ binding mode, in which KIR binds across both the $\alpha 1$ and $\alpha 2$ helices of HLA. This orientation is analogous to T cell receptor (TCR)/HLA interaction, with the tandem D1 and D2 domains of KIR assuming positions similar to the $\mathrm{V} \alpha$ and $\mathrm{V} \beta$ domains of TCRs (16). Both KIRs and TCRs bury similar amounts of solvent-accessible surface area (1500-1800 $\left.\AA^{2}\right)$ and exhibit comparable shape complementarity $(\mathrm{Sc}=0.45-0.71)$ when complexed with HLA molecules. There are, however, unique features in the KIR/HLA recognition. For example, TCRs prefer to interact with peptides at the central P4-P6 posi- tions (17), whereas KIR binding is centered toward the C-terminal end P7-P8 position of the peptide. The footprint of a KIR on HLA is distinct from but overlaps that of TCRs, precluding simultaneous binding.

The ligand-binding region of a KIR comprises six surface loops at the interdomain hinge area. In contrast to TCR/HLA interfaces that consist of predominately nonpolar van der Waals and hydrogen-bonding interactions, the KIR/HLA interface contains a significant amount of charge complementarity. In all, a KIR provides six acidic residues and HLA contributes six basic residues to the interface, resulting in the formation of four salt bridges between KIR2DL2 and HLA-Cw3 (Glu21Arg69, Glu106-Arg151, Asp135-Arg145, and Asp183-Lys146). The relevance of this charge complementarity to the KIR/HLA recognition was investigated by individually mutating the three salt-bridge-forming residues of KIR2DL2 (Glu106A, Asp135H, and Asp183A). Equilibrium binding measurements using surface plasmon resonance (SPR) techniques revealed drastic reductions in HLACw3 affinity for all three mutants (Table 1), highlighting the importance of these salt bridges and suggesting a critical binding threshold for recognition. In addition to the salt bridges, there are seven hydrogen bonds and two hydrophobic patches present at the receptor-ligand interface.

Allotype specificity is an integral characteristic of a KIR/HLA interaction. For example, KIR2DL1 interacts with HLA-Cw2, 4, 5, 6 , and 15, whereas KIR2DL2 recognizes HLA$\mathrm{Cw} 1,3,7$, and 8 allotypes. Earlier studies have implicated KIR2D residue 44 and the HLA-C heavy-chain residue 80 as being critical in allotypic recognition. Interestingly, residue 80 is the only class I interface residue that varies among the two classes of KIR-specific HLA-C allotypes. It is an Asn in HLA-Cw1, 3, 7, and 8, but a Lys in HLA-Cw2, 4, 5, 6, and 15 allo- 


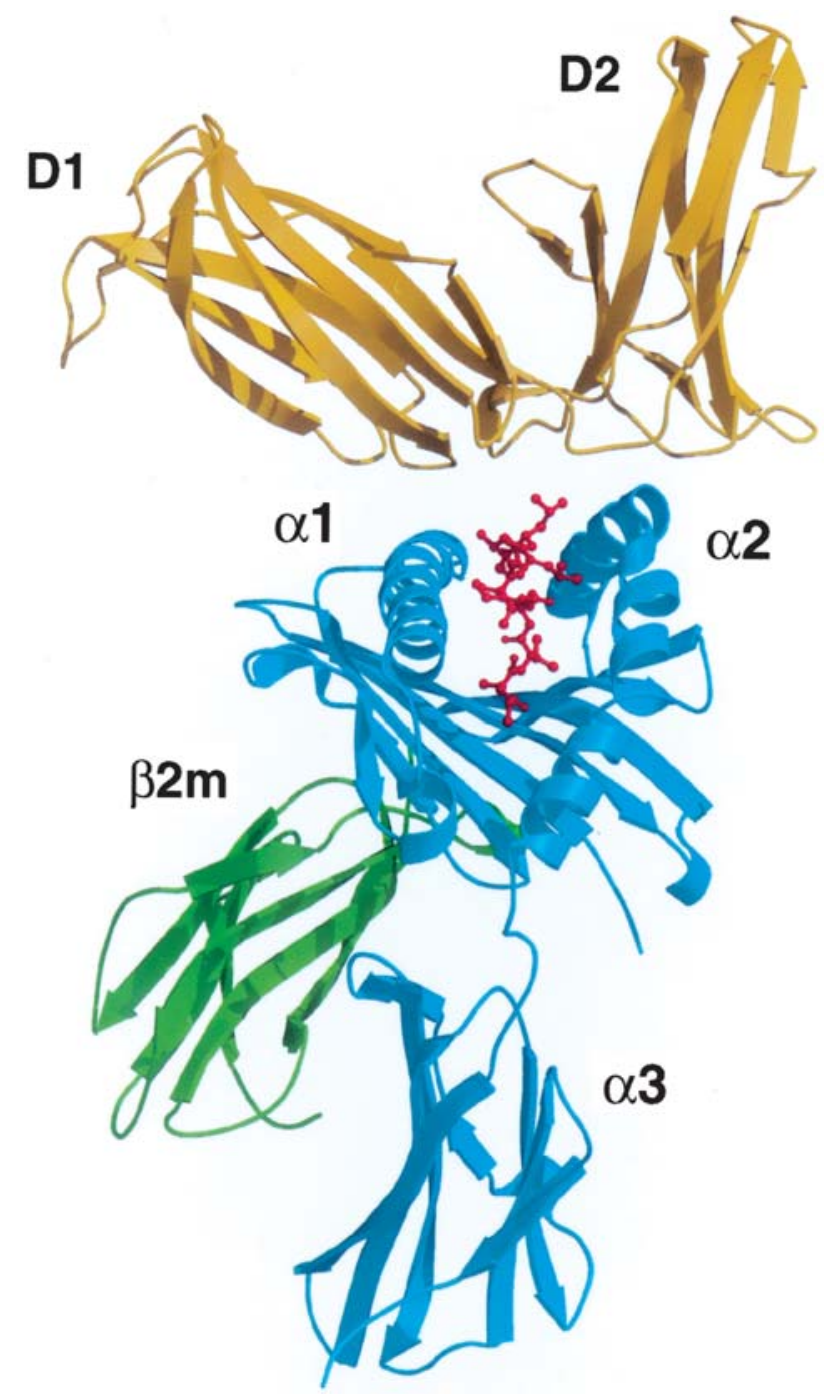

Fig. 1. The structure of KIR2DL2 and HLA-Cw3 complex. The $\beta 2 \mathrm{~m}$ domain, the HLA-Cw 3 heavy chain, and the GAV peptide are colored green, blue, and red, respectively. The KIR molecule is colored yellow.

types. In the KIR2DL2/HLA-Cw3 complex, Lys44 of the KIR makes a hydrogen bond to Asn80 of HLA-Cw3. KIR2DL1, which does not bind to HLA-Cw3, has a Met at position 44 instead and cannot make this hydrogen bond. Alternatively, Lys44 of KIR2DL2 would have unfavorable electrostatic and steric interactions with Lys80 of HLA-Cw4, thus destabilizing the KIR/HLA complex.
In addition to the class I MHC residues, the associated peptides are also crucial for KIR recognition (18). In the structure of KIR2DL2/HLA-Cw3 complex, the receptor is situated over the peptide residues P7-P8, resulting in a hydrogen bond between Gln71 of the receptor and the GAV peptide. This interaction brings Ala8 sufficiently close to the KIR that it may constrain the size of the P8 side 
Table 1. Dissociation Constants for KIR2DL2/ HLA-Cw3 Interaction

\begin{tabular}{|c|c|}
\hline & $K_{D}(\mu M)$ \\
\hline \multicolumn{2}{|l|}{ KIR mutant } \\
\hline Wild type & 28 \\
\hline R33A & 30 \\
\hline K44M & $>400$ \\
\hline Y105A & $>400$ \\
\hline E106A & 185 \\
\hline D135H & $>400$ \\
\hline D183A & $>400$ \\
\hline \multicolumn{2}{|l|}{ Cw3 peptide } \\
\hline GAVDPLLAL & 9.5 \\
\hline$\ldots \ldots s$. & 42.3 \\
\hline$\ldots \ldots v$. & 525 \\
\hline ..... & $>600$ \\
\hline$\ldots \ldots k$ & $>600$ \\
\hline AAADAAAAL & 48.5 \\
\hline TAMDVVYAL & 38 \\
\hline QAISPRTL & 74 \\
\hline HLA-E peptide & $>600$ \\
\hline
\end{tabular}

chain for KIR/HLA interaction. Substitutions at the P8 position of the GAV peptide from Ala to Ser, Val, Tyr, and Lys revealed that the affinity of KIR2DL2 for HLA-Cw3 decreases as the size of the peptide P8 side chain increases. In fact, P8 residues larger than Val essentially abrogated KIR2DL2 binding (Table 1). Interestingly, HLA-Cw3 complexed with a nine-residue TAMDVVYAL peptide, or a motif peptide AAADAAAAL, both differ from GAV except at the P4, P8, and P9 positions, bind to the receptor with affinities similar to that of the wild-type GAV peptide. These results confirm that residues other than $\mathrm{P} 7$ and P8 do not contribute significantly to the receptor recognition.

A distinguishing characteristic of KIR/HLA interaction is that the interface is more conserved than TCR/HLA interfaces. For example, only 8 out of 16 HLA-A2 residues in contact with the A6 TCR are conserved among HLA-A alleles. This reflects the very differ- ent functions of KIRs and TCRs in the innate and adaptive immune system, respectively. KIR molecules recognize large groups of HLA alleles bound to diverse peptides, essentially detecting whether or not various HLA allotypes are being expressed on target cells. Clonotypic TCRs, on the other hand, recognize particular HLA/foreign peptide complexes with a high specificity in order to discern the presence of an intracellular pathogen. As a component of the first line of defense, NK cells in the innate immune system must respond rapidly without the luxury of time. Consequently, NK-cell receptors such as KIR are germline encoded, resulting in a limited number of receptor types per individual. However, effective immunosurveillance of class I HLA expression entails recognition of numerous HLA alleles, many more than the number of KIR receptor types available. KIR accomplishes this by recognizing conserved residues within polymorphic HLA molecules.

\section{Structure of the Activating Receptor NKG2D in Complex with ULBP}

NKG2D, a member of the CTLR superfamily and distantly related to NKG2A, B, C, and E, is found on NK cells to trigger cytotoxicity against certain tumor cells and on $\mathrm{CD}^{+} \alpha \beta \mathrm{T}$ and $\gamma \delta$ T cells to provide a costimulatory signal against virally infected cells (19-22). Efforts in searching for NKG2D ligands have led to the identification of MICA and B and ULBPs in human and Rae-1 and $\mathrm{H} 60$ in mice $(19,23,24)$. MICA and B display $\alpha 1, \alpha 2$, and $\alpha 3$ domains similar to those found in class I MHC heavy chains, but do not associate with peptides and $\beta 2$-microglobulin (25). ULBP, Rae-1, and $\mathrm{H} 60$ are also class I-like molecules but contain only the $\alpha 1$ and $\alpha 2$ domains, and are glycosylphatidylinositol (GPI) anchored (26). The sequence identities among MICs and ULBPs are about 25\%, making NKG2D a 


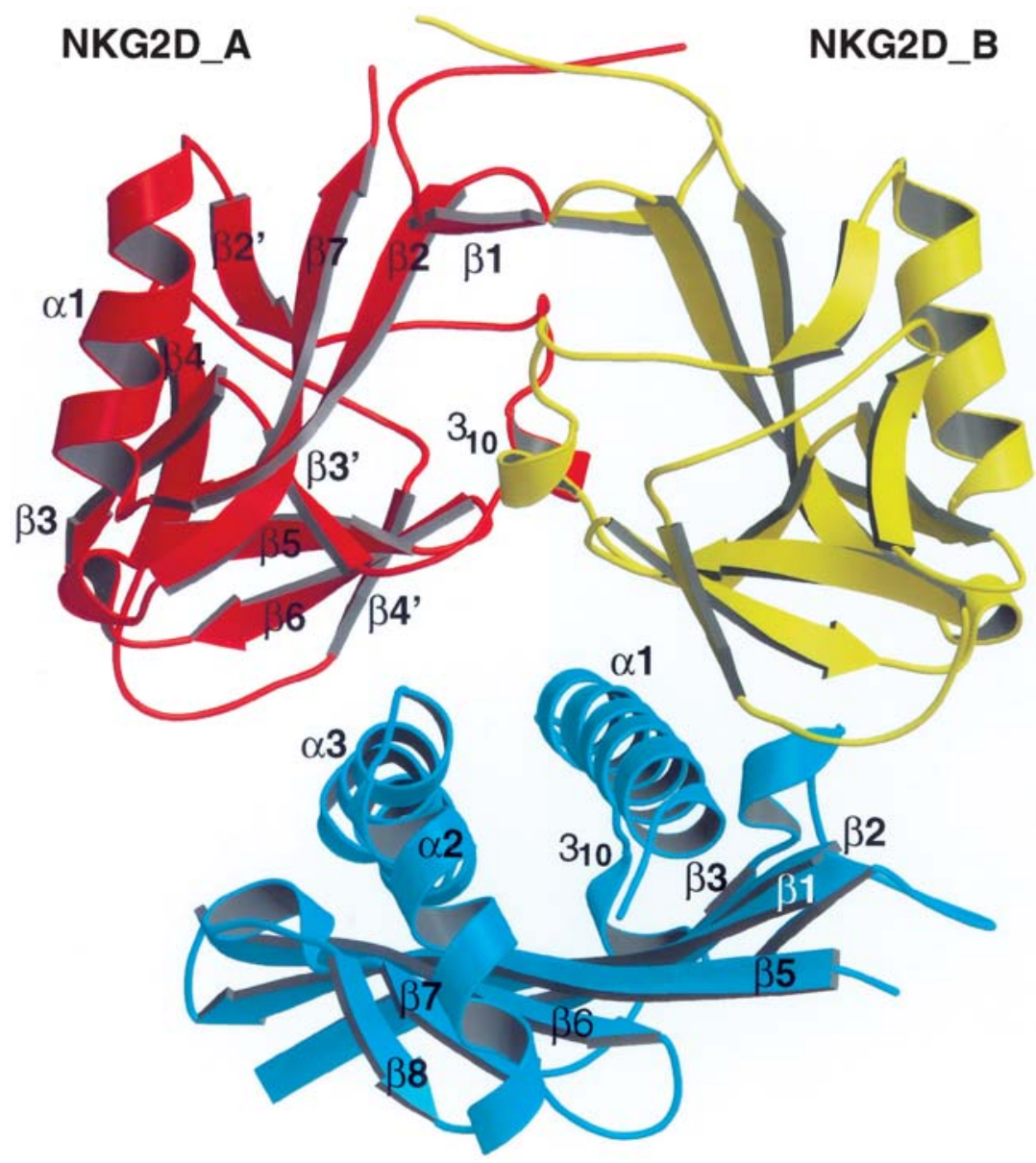

Fig. 2. The structure of the NKG2D-ULBP3 complex. Subunits A and B of the NKG2D homodimer are shown in red and yellow, respectively. ULBP3 is colored in blue.

unique activating receptor with the ability to bind diverse MHC class I-like ligands. The structural basis of such broad specificity of NKG2D is yet to be determined.

The structure of a human NKG2D receptor in complex with its ligand ULBP3 has been determined to 2.6 Å resolution (27). The overall shape of the NKG2D/ULBP3 complex resembles a crab preying on a seashell (Fig. 2). The crab-shaped receptor uses its claw-shaped $\beta$-strands and loops, at the end opposite to the $\mathrm{N}$ - and C-termini, to grab on the ridge-shaped helical surface of ULBP3. This mode of com- plex formation is also observed in the NKG2D/MICA complex. The interaction between a homodimeric NKG2D and the asymmetrical ULBP3 results in an asymmetrical receptor subunit orientation slightly different from that observed in the dyad-related ligand-free murine receptor. Although all classical MHC molecules present peptides, no peptide was found in the corresponding peptide-binding region of ULBP3. The spacing between the $\alpha$-helices of ULBP3 ranges from 8 to $14 \AA$ A, narrowest among all MHC homologs. In addition, a salt bridge, conserved in 
all three ULBP sequences, is formed across the groove between Asp 87 of the $\alpha 1$-helix and Lys 151 of the $\alpha 2$-helix and further stabilizes the closed groove conformation.

The interface shape complementarity value $\mathrm{Sc}$ is 0.65 between the receptor and ULBP3 (28), similar to that between NKG2D and MICA (29) and greater than those between KIR and HLA or between TCR and MHC $(\mathrm{Sc}=0.5-0.6)(30)$. The total buried interface is $1930 \AA^{2}(8.2 \%$ and $10.7 \%$ of the respective NKG2D and ULBP3 surface), slightly smaller than the $2180 \AA^{2}$ buried between NKG2D and MICA (29) but larger than the 1560- $\AA^{2}$ interface between the KIR and HLA (30), or the 1700-1800 $\AA^{2}$ between TCR and MHC (31-33). Each receptor subunit contributes approximately half of the total interface area. In all, six receptor segments, three similar segments from each subunit, interact with the ligand. The interface is stabilized primarily by a network of 10 hydrogen bonds, 2 salt bridges, and hydrophobic interactions.

\section{NKG2D/ULBP3 Recognition Displays Conformational Plasticity}

Conformational plasticity or induced-fit binding refers to a situation in which a receptor undergoes ligand-specific conformational adjustments upon complex formation. This is opposed to the lock-and-key recognition, where no conformational adjustment takes place upon complex formation. Depending on the receptor-ligand system, both induced-fit and lock-and-key modes of recognition have been observed. Many cytokine receptor activations, certain $\mathrm{T}$ cell receptor and class I MHC recognition (34), and some antigen-antibody complexes are thought to involve induced-fit mechanisms. The examples of lock-and-key recognition include the KIR/HLA complex and the adhesion CD2/CD58 complex (30, 35,36). NKG2D/ULBP3 complex displays characteristic features of an induced-fit recognition. First, the binding of the ULBP resulted in an asymmetric orientation of the homodimeric NKG2D subunits. A similar adjustment in the receptor subunits was also observed in the NKG2D/MICA complex structure (29). Second, different receptor residues were recruited from each subunit to match the asymmetrical ULBP3 surfaces. Although both subunits of NKG2D employ the same loops to bind ULBP3, the actural interface residues varies between the subunits as a result of interacting with different ULBP3 residues. For example, among the 12 ULBP3 residues that contact NKG2D, only 2, Arg 82 and Asp 169, are conserved in MICA. However, they do not mediate the same interface contacts. This receptor conformational plasticity in both the domain and the side-chain orientations enables the receptor to adapt various ligand surfaces while preserving an overall receptor-ligand docking orientation.

\section{Activation of CD16 Requires the Formation of Immune Complexes}

Binding of immune complexes to CD16 (FcyRIII) activates NK-cell-mediated antibody-dependent cellular cytotoxicity (ADCC). Fc receptors have been described for all classes of immunoglobulins: $\mathrm{Fc} \gamma \mathrm{R}$ and neonatal $\mathrm{FcR}$ $(\mathrm{FcRn})$ for $\operatorname{IgG}, \mathrm{Fc \varepsilon R}$ for $\operatorname{IgE}, \mathrm{Fc} \alpha \mathrm{R}$ for $\mathrm{IgA}$, $\mathrm{Fc} \delta \mathrm{R}$ for $\operatorname{IgD}$, and $\mathrm{Fc} \mu \mathrm{R}$ for $\operatorname{IgM}(37-40)$. Among them, Fc $\gamma$ RI and FceRI are high-affinity Fc receptors with dissociation constants ranging from $10^{-8}$ to $10^{-10} \mathrm{M}$. All other IgG receptors, such as Fc $\gamma$ RII and Fc $\gamma$ RIII, are lowaffinity receptors with dissociation constants $10^{-5}-10^{-7} M$. The high-affinity receptors FceRI and Fc $\gamma$ RI are activated by monomeric immunoglobulins. Under physiological conditions, the low-affinity receptors Fc $\gamma$ RII and Fc $\gamma$ RIII require the formation of multivalent immune complexes for their activation. 
All Fc $\gamma$ receptors show high degree of sequence identity in their extracellular portion (50-96\%), but differ significantly in their cytoplasmic domains. Some Fc $\gamma$ receptors contain the immunoreceptor tyrosine-based activation motif (ITAM) (FcyRIIA,C) or the corresponding inhibitory motif (ITIM) (Fc $\gamma$ RIIB) in their cytoplasmic tails. Others (Fc $\gamma R \mathrm{RI}$ and Fc $\gamma$ RIIIA) require the association of the ITAM containing $\mathrm{Fc}$ receptor common $\gamma$-chain or $\mathrm{T}$ cell receptor $\zeta$ chain for signaling.

The crystal structure of a human Fc $\gamma$ RIII in complex with the $\mathrm{Fc}$ portion of a human $\mathrm{IgG} 1$ has been determined to 3.0 Å resolution $(41,42)$ (Fig. 3). The receptor binds to the horseshoe opening, the lower hinge region, of the $\mathrm{Fc}$, breaking down the dyad symmetry of the Fc. This binding mode excludes the possibility of having a second receptor interacting with the same $\mathrm{Fc}$ molecule, resulting in a $1: 1$ stoichiometry for the receptor-Fc recognition. This ensures the need for antigens and, hence, the immune complexes in forming an activation receptor aggregation and eliminates the possibility of Fc-mediated receptor aggregation as suggested in a $2: 1$ stoichiometry. Approximately $1453 \AA^{2}$ solvent accessible area is buried upon FcyRIII-Fc complex formation. All contacts to the $\mathrm{Fc}$ are made exclusively through the receptor D2 domain, whereas its D1 domain is positioned above, making no contacts with $\mathrm{Fc}$ (Fig. 3). On the Fc side of the complex, interactions with the receptor are dominated by residues Leu 234Pro 238 of the lower hinge, consistent with the results from earlier mutational studies (43). A network of nine hydrogen bonds, including both the main-chain and the side-chain ones, is formed between the receptor and Fc. A proline sandwich is formed between Trp 90, Trp 113 of the receptor, both conserved in all human Fc $\gamma$ and $F c \varepsilon$ receptors sequences, and Pro 329, invariant among all $\mathrm{Fc}$ sequences. This hydrophobic core extends further to include Val 158, the aliphatic side chain of Lys 161 from the receptor and Leu 235 from. Mutations of both Trp 113 and Lys 161 in Fc $\gamma$ RIII lead to the loss in receptor function $(44,45)$.

The structural comparison between the Fc $\gamma$ RIII-Fc complex and the FceRI-Fc complex shows a similar mode of receptor-ligand recognition and the two complexes can be superimposed to a root mean square (rms) deviation of $1.5 \AA$ between all $\mathrm{C} \alpha$ atoms. However, significant differences are also observed. First, there are more extensive hydrophobic interactions between the FceRI and IgE-Fc than between FcyRIII and IgG-Fc. Second, more hydrogen bonds and salt bridges exist at the FceRI-Fc interface compared to Fc $\gamma$ RIII-Fc. Interestingly, the hydrogen bonds in the FceRI-Fc interface are formed mostly between the side-chain atoms, whereas those in the Fc $\gamma \mathrm{RIII}-\mathrm{Fc}$ interface are formed primarily between the main-chain atoms or between the main-chain and side-chain atoms. There are two salt bridges observed between FceRI and Fc, but only one is found between Fc $\gamma$ RIII and Fc. The comparison suggests that multiple interactions contribute to the observed receptor-ligand affinity difference and that the high-affinity recognition contains more extensive hydrophobic interface area as well as more prominent electrostatic interactions.

The study on the binding of peptides with the sequences of lower hinges of $\operatorname{IgG} 1, \operatorname{IgG} 2$, and $\mathrm{IgG} 4$ (denoted as pIgG1, pIgG2, and pIgG4) to Fc $\gamma$ RIII was carried out in an attempt to explain the receptor IgG isotype specificities (46). The receptor-peptide binding constants ranged from 100 to $400 \mu M$. The results of this study show that pIgG2 and pIgG4 have nearly the same affinity to Fc $\gamma$ RIII as pIgG1. Replacing Leu with Phe in pIgG4 or changing Glu-Leu-Leu-Gly to Pro-Val-Ala in pIgG2 in addition to a single-residue deletion makes little difference in their affinity to the receptor, sug- 


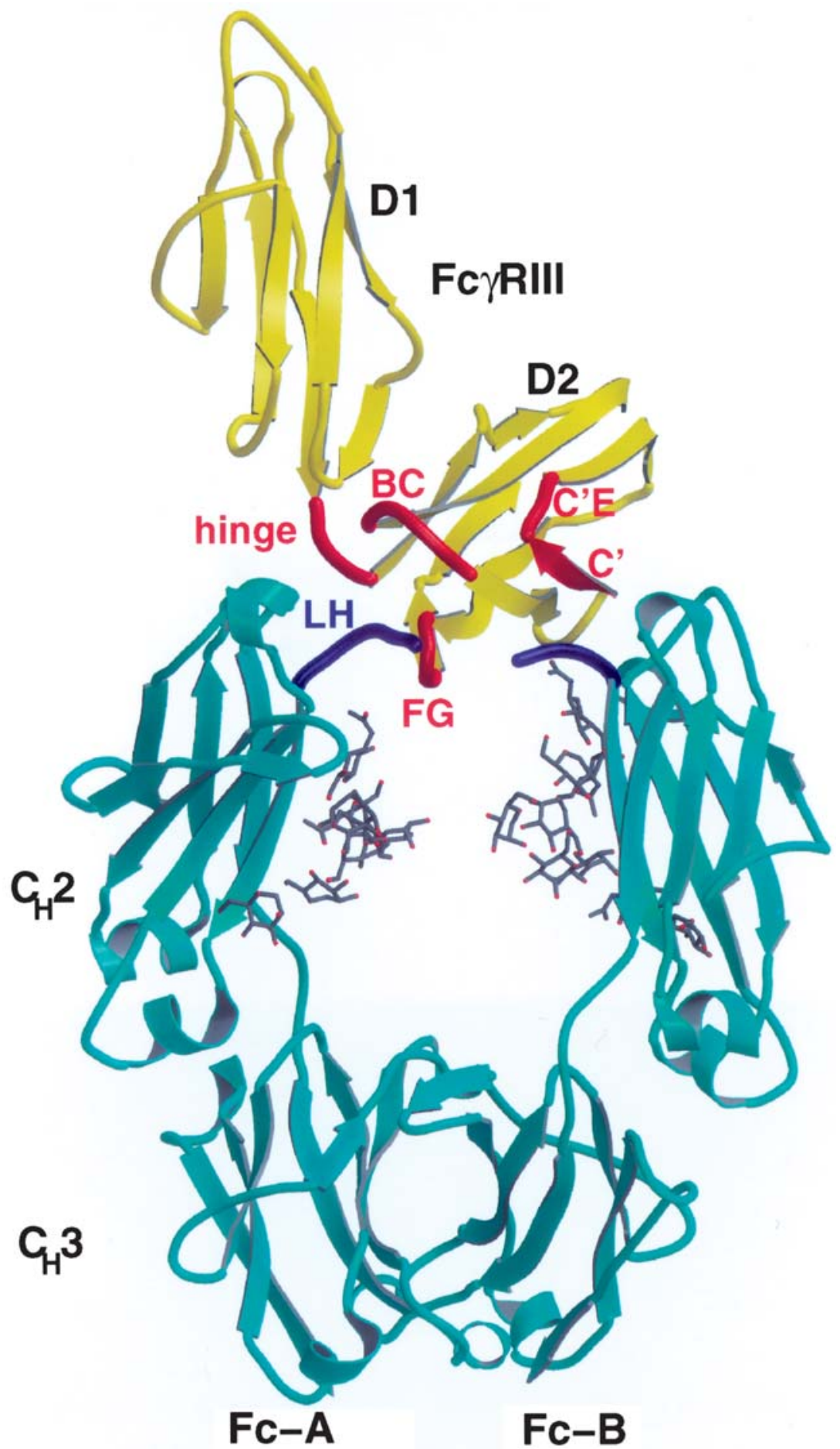

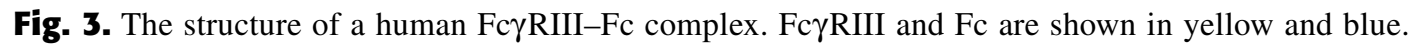
Carbohydrate moieties are shown in gray. The receptor-ligand interface loops are highlighted. 
gesting that factors other than the lower-hinge amino acid composition play important roles in determining receptor-IgG-subtype affinity. Additionally, this study was aimed at the ability of lower-hinge peptides to block antibody-receptor interaction. The fact that these lower-hinge peptides are able to block the $\mathrm{Fc}$ binding to Fc $\gamma \mathrm{RIII}$ revealed the possibility of designing new therapeutic compounds to control antibody-mediated autoinflammatory response in the case of certain autoimmune diseases, such as rheumatoid arthritis (47).

The contribution of glycosylation of $\mathrm{Fc}$ to the function of immunoglobulins has been debated over the years (48-50). In both Fc $\gamma$ RIII-Fc and FceRI-Fc complex structures, the carbohydrates have few direct interactions with the receptors $(41,42,51)$. To understand the apparent discrepancy between the known importance of this glycosylation to the function of FcyRIII and the lack of a direct contact at the receptor-Fc interface, BIAcore-binding studies were carried out using a deglycosylated IgG1 and its Fc fragment as the ligand (46). Upon enzymatic deglycosylation, the Fc $\gamma$ RIII affinity to IgG1 decreased 10-fold to 15 -fold, whereas the receptor affinity to the $\mathrm{Fc}$ fragment was undetectable. Because the carbohydrates contact little with the receptor, one possible role for the carbohydrates is to function as a surrogate hydrophobic core between the two chains of $\mathrm{Fc}$, thereby stabilizing the IgG lower hinge in an active receptor-binding conformation.

\section{Acknowledgments}

The author wish to thank J. Boyington and S. Radaev for preparation of the figures and insightful discussions.

\section{References}

1. Lanier LL: Annu Rev Immunol 1998;16:359-393.

2. Long EO: Annu Rev Immunol 1999;17:875-904.

3. Colonna M, Samaridis J: Science 1995;268:405-408.

4. D'Andrea A, Chang C, FranzBacon K, McClanahan T, Phillips JH, Lanier LL: J Immunol 1995; 155:2306-2310.

5. Steffens U, Vyas Y, Dupont B, Selvakumar A: Tissue Antigens 1998;51:398-413.

6. Wilson MJ, Torkar M, Trowsdale J: Tissue Antigens 1997;49: 574-579.

7. Khakoo SI, Rajalingam R, Shum BP, Weidenbach K, Flodin L, Muir DG, et al.: Immunity 2000;12: 687-698.

8. Samaridis J, Colonna M: Eur J Immunol 1997;27:660-665.

9. Borges L, Hsu ML, Fanger N, Kubin M, Cosman D: J Immunol 1997;159:5192-5196.

10. Colonna M, Navarro F, Bellon T, Llano M, Garcia P, Samaridis J, et al.: J Exp Med 1997;186: 1809-1818.
11. Meyaard L, Adema GJ, Chang C, Woollatt E, Sutherland GR, Lanier LL, et al.: Immunity 1997; 283-290.

12. Arm JP, Gurish MF, Reynolds DS, Scott HC, Gartner CS, Austen KF, et al.: J Biol Chem 1991;266: 15,966-15,973.

13. Kubagawa H, Burrows PD, Cooper MD: Proc Natl Acad Sci USA 1997;94:5261-5266.

14. Hayami K, Fukuta D, Nishikawa Y, Yamashita Y, Inui M, Ohyama Y, et al.: J Biol Chem 1997;272: 7320-7327.

15. Boyington JC, Motyka SA, Schuck P, Brooks AG, Sun PD: Nature 2000;405:537-543.

16. Ding YH, Smith KJ, Garboczi DN, Utz U, Biddison WE, Wiley DC: Immunity 1998;8:403-411.

17. Garcia KC, Degano M, Stanfield RL, Brunmark A, Jackson MR, Peterson PA, et al.: Science 1996; 274:209-219.

18. Wagtmann N, Biassoni R, Cantoni C, Verdiani S, Malnati MS, Vitale M, et al.: Immunity $1995 ; 2$ : 439-449.
19. Bauer S, Groh V, Wu J, Steinle A, Phillips JH, Lanier LL, et al.: Science 1999;285:727-729.

20. Wu J, Song Y, Bakker AB, Bauer S, Spies T, Lanier LL, et al.: Science 1999;285:730-732.

21. Groh V, Rhinehart R, RandolphHabecker J, Topp MS, Riddell SR, Spies T: (2001) Nat Immunol 2001;2:255-260.

22. Das H, Groh V, Kuijl C, Sugita M, Morita CT, Spies T, et al.: Immunity 2001;15:83-93.

23. CerwenkaA, BakkerAB, McClanahan T, Wagner J, Wu J, Phillips JH, et al.: Immunity 2000;12:721-727.

24. Diefenbach A, Jamieson AM, Liu SD, Shastri N, Raulet DH: Nat Immunol 2000;1:119-126.

25. Li P, Willie ST, Bauer S, Morris DL, Spies T, Strong RK: Immunity 1999;10:577-584.

26. Cosman D, Mullberg J, Sutherland CL, Chin W, Armitage R, Fanslow W, et al.: Immunity $2001 ; 14$ : 123-133.

27. Radaev S, Rostro B, Brooks AG, Colonna M, Sun PD: Immunity 2001;15:1-20. 
28. Lawrence MC, Colman PM: J Mol Biol 1993;234:946-950.

29. Li P, Morris DL, Willcox BE, Steinle A, Spies T, Strong RK: Nat Immunol 2001;2:443-451.

30. Boyington JC, Motyka SA, Schuck P, Brooks AG, Sun PD: Nature 2000;405:537-543.

31. Garboczi DN, Ghosh P, Utz U, Fan QR, Biddison WE, Wiley DC: Nature 1996;384:134-141.

32. Garcia KC, Degano M, Stanfield RL, Brunmark A, Jackson MR, Peterson PA, et al.: Science 1996; 274:209-219.

33. Reinherz EL, Tan K, Tang L, Kern P, Liu J, Xiong Y, et al.: Science 1999;286:1913-1921.

34. Garcia KC, Degano M, Pease LR, Huang M, Peterson PA, Teyton L, et al.: Science 1998;279: 1166-1172.
35. Radaev S, Motyka S, Fridman WH, Sautes-Fridman C, Sun PD: J Biol Chem 2001;276:16,469-16,477.

36. Wang JH, Smolyar A, Tan K, Liu JH, Kim M, Sun ZY, et al.: Cell 1999;97:791-803.

37. Fridman WH: Curr Opin Immunol 1993;5:355-360.

38. Ravetch JV, Clynes RA: Annu Rev Immunol 1998;16:421-432.

39. Hulett MD, Hogarth PM: Adv Immunol 1994;57:1-127.

40. Daeron M: Int Rev Immunol 1997;16:1-27.

41. Radaev S, Fridman W-H, SautesFridman C, Sun PD: The structure of a human type III Fecgamma receptor in complex with Fc. J Biol Chem 2001;276:16,469-16,477.

42. Sondermann P, Huber R, Oosthuizen V, Jacob U: Nature 2000; 406:267-273.
43. Tamm A, Schmidt RE: Int Rev Immunol 1997;16:57-85.

44. Tamm A, Kister A, Nolte KU, Gessner JE, Schmidt RE: J Biol Chem 1996;271:3659-3666.

45. Hibbs ML, Tolvanen M, Carpen O: J Immunol 1994;152:4466-4474.

46. Radaev S, Sun PD: J Biol Chem 2001;276:16,478-16,483.

47. Vaughan JH: Arthritis Rheum. 1993;36:1-6.

48. Jefferis R, Lund J, Pound JD: Immunol Rev 1998;163: 59-76.

49. Kulczycki A Jr, Vallina VL: Mol Immunol 1981;18:723-731.

50. Lund J, Tanaka T, Takahashi N, Sarmay G, Arata Y, Jefferis R: Mol Immunol 1990;27:1145-1153.

51. Garman SC, Wurzburg BA, Tarchevskaya SS, Kinet JP, Jardetzky TS: Nature 2000;406:259-266. 